\title{
An Experimental Analysis Of Dependency On Automation And Management Skills
}

\author{
Ms. Elena Rosemaro \\ Department of Management Studies, VIM Australia \\ elenarosemaro@gmail.com
}

\begin{tabular}{|c|c|}
\hline Article History & Abstract \\
\hline $\begin{array}{l}\text { Article Submission } \\
2 \text { September } 2013 \\
\text { Revised Submission } \\
17 \text { February } 2014 \\
\text { Article Accepted } \\
15 \text { March } 2014 \\
\text { Article Published } \\
31^{\text {st }} \text { March } 2014\end{array}$ & $\begin{array}{l}\text { With the increase in the earth's population, nowadays automation is growing at a } \\
\text { very fast speed and many different types of strategies are being made and } \\
\text { implemented for better understanding and interaction with humans. With the } \\
\text { advancement in automation, the workplace is changing and is managed in a very } \\
\text { different way than the old times. These technologies will change a lot of changes in } \\
\text { all the sectors of life like in education, banking, industrial, medical, and many more, } \\
\text { and researchers also say that it will bring growth in productivity. There is a huge } \\
\text { demandfor the fast-growing business in this highly competitive market so companies } \\
\text { are making their way to examine, updating and even modern work is on its way that } \\
\text { is automation in all business processes. So to continually evolve with the } \\
\text { technologies we need to automate our business and managed it accordingly so that } \\
\text { there is improved effective and productive work. } \\
\text { Keywords: Automation,Management Skills }\end{array}$ \\
\hline
\end{tabular}

\section{Introduction}

There are many challenges in handling the business process in different departments which include many stakeholders. Whenever a work related to databases is processed, then manually it takes more time and does not show the transparency for too complex problems and is not manually it becomes more difficult to visualize, the level of understanding also decreas. So, to solve such problems, a solution is an automation management system where workflow is managed automatically with the less human workforce, and with more machine tasks, the business also stuck up on what to be performed at what time and error detection became easier with great visibility. Business team workers must work effectively so that there is proper control and coordination among team members when the management of the business process is done through Artificial Intelligence then information needed is acquired regardless of location, a better sort of communication can be set up.

Software for easy management is designed by IBM known as IBM rational ClearQuest where real-time staus and reporting can be done to deliver value-added business. Information can be accessed whenever needed. It is designed for managing different aspects of a complex business process

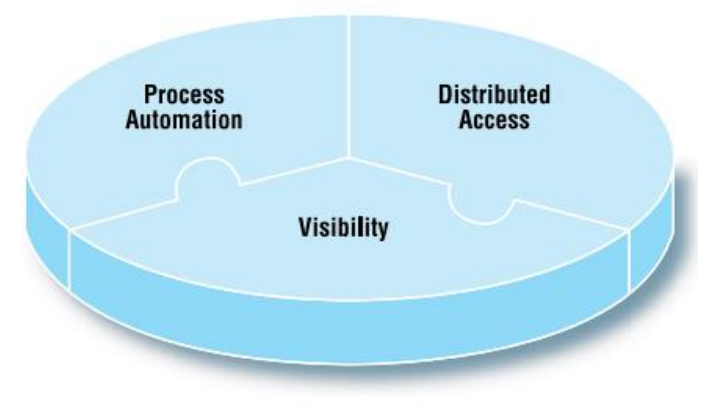

Fig 1: Distributed Organization with proper visibility 
The above fig 1 is explained as to how the process automation is done with visibility of processes with proper distributed access. The workflow is selected and the business process runs with it. The fast report analysis is to be done so management of the business is done with proper visibility on all the tasks so that whatever changes are required that can be updated immediately. Data once updated is made available for other team members and can more across the globe.

\section{The Management System of Workflow}

The work done should be hasslefree and seamless and the workflow management system helps to automate this work and managed its working models and ideas. It also creates deadlines and boundaries and also creates an area where that to be executed. A set of rules is defined when the workflow management system starts. The following fig 2 gives all components for its working model, tasks. The three main working parts are:

- Workflow portal which contains workflow editor and workflow modeling and definition.

- Workflow Enactment Engine which has language parser, task dispatcher, workflow scheduler where algorithms are scheduled, resource allocation, fault-tolerant management, negotiation services. The main part of this system is the engine where are scheduling, allocations, language parsing analysis is done.

- The last part is the resource broker which contains a public cloud, private cloud, hybrid cloud. This part acts as a resource person for all the types of clouds and communicates for desired results.

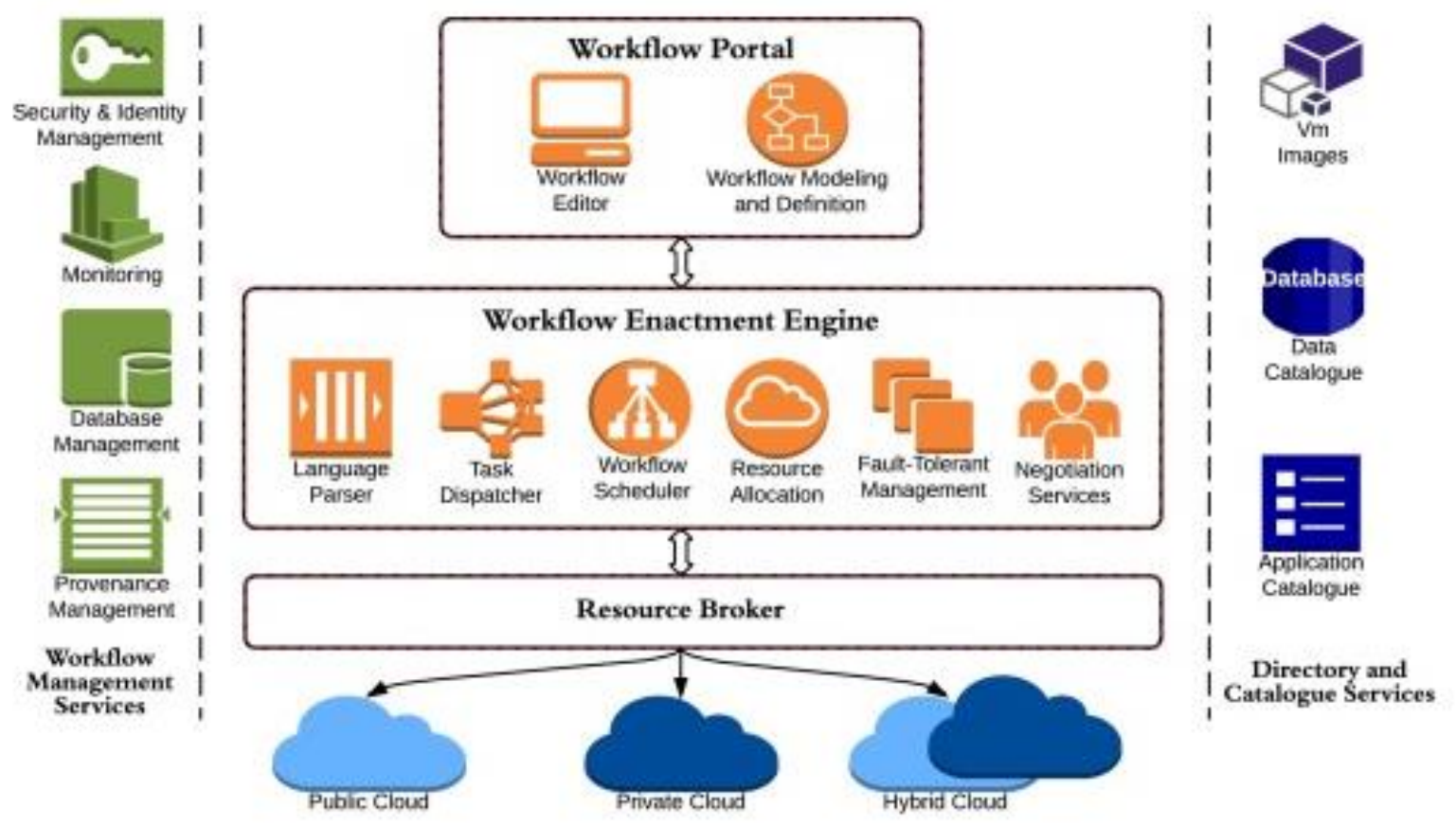

Fig 2: Workflow management system architecture

This architecture of the workflow management system shows how the monitoring is done in response to the security and by managing the database by using the VM images, data catalog, application catalog. The second stage act as the main resource for the workflow management system as all the detailing is done in this stage only. It makes available all the essential services to provide the proper flow management system. The security service provides secure and authentic work. Next to the monitoring tools which monitor the components present in the system and with proper timing and need it to raise the alarm for the disturbance created in the system the data is stored in the database and final data results of workflow system also get stored there. Provenance management services take up all the important information like controlling data, execution of information, input-output files, etc as it is vital for interpreting the data, maintain the quality of data, and giving the proper results. 


\section{III.Skill Shifts in Workforce}

The accumulation of automation into the working area comes with the intermixing of human skills rather than substitution of jobs. It does not change the job but some skills are accumulated in the jobs performed. A person's role in the company is that he/she should have the skill to understand the project and develop new skills which relate them to the automation developed in the company. Suppose a software developer is there for a particular company then requires the many sorts of skills ranging from coding to testing and understanding the needs of the client and also to supervise the junior who are developing the codes.

The skills of a manager are categorized who are ready for automation as follows:

- Process-oriented skills which includes hand to hand problem solving and setting the outcome in a predictable way. This skill is for the activities people are doing today like filling objects, accounting.

- Reasoning skills need intelligence which requires skills like reasoning, knowledge about the product, analytics understanding, logic, language knowledge, etc.

- Creativity and functional skills which require the strategy of a person to solve, manage, design, and make sense of things related to social and economical skills

Automation will make a great change in the skills mentioned above. Machine do much better work than humans and mostly all work done by machine is human-oriented as $80 \%$ process skill will be done by AI whereas the $51 \%$ of reasoning skill is done by machine $\mathrm{s}$ and rest by humans. There will be decay in the occupation of humans because they need to develop the skills which are needed for the operation of machines. More than $80-85 \%$ of cross-functional tasks are performed by the machine shortly.

It is not that the introduction of AI will replace the jobs for the people but it will show a great impact as it creates jobs for the new with their new ideas and functionalities. But the tension socially and politically may arise as the risk in income and unemployment can be there for the person with less skills. The block of AI will not help the companies as AI will always benefit and give increased productivity.

A highly creative and multitasking skill team would be needed to solve the complex problems so that digitally the machine is transforming and well balance should be maintained and marketing strategies should be planned to keep the balance between the transformation.

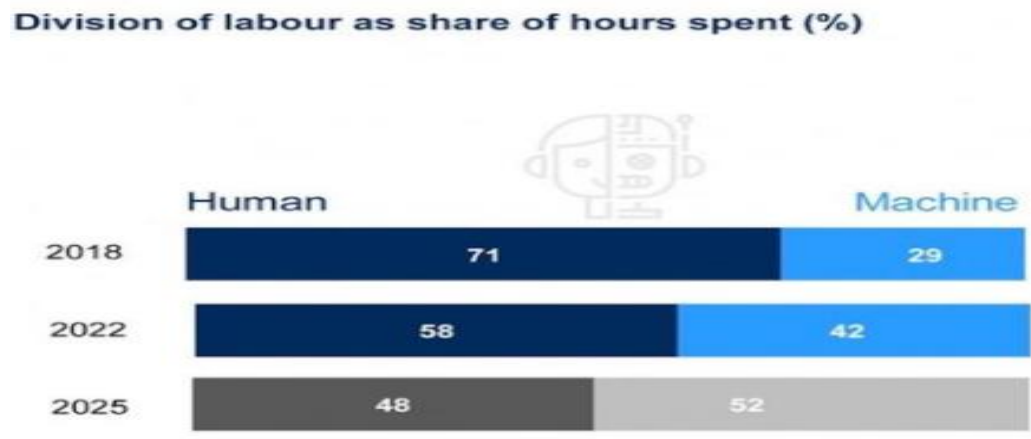

Fig 3: Rate of automation

The fig 3 shows how the rate of automation increases with the comparison of humans like for the year $201871 \%$ of humans work as the management head and only $29 \%$ of work was done by the machine. But as time is rising the technology is advancing by the year $202258 \%$ of human work will be done and more than $42 \%$ of work will be completed by the machines only. And by the end of the year 2025, 52\% of work will be done by the machine only and no database work will be required by humans to do by their own all workflow engine work will be 
completed by the machine with good quality and error-free. This figure shows the division of labor with the human share for the present and the upcoming years.

The companies are expecting differently with the advancement of the technology as some are thinking that 50\% of companies to decrease the work by the automation by 2022. But some are expecting that more workforce will be required to create new expertise. It has been surveyed that companies and business people are reskilling their employees so that they can work as an individual in the environment and can transform the workforce with the automation.

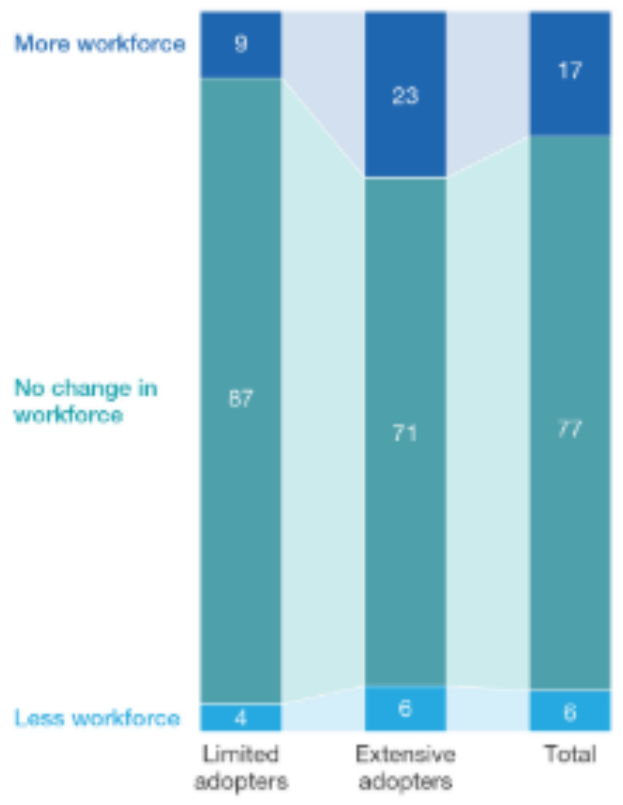

Fig 4: Expected workforce in the companies

Working conditions will alter when the workforce will change as it allows companies to work at different levels. High skill workers will be needed to perform tasks that are automated and a network of teams will be required to further divide the work among themselves.

As described in figure 4 that 77 percent of the workforce does not change with the advancement of the AI or after introducing the automation in the company. Whereas 17 percent requires to grow over Europe and the United States with a more new workforce. The model of jobs and skills will change, however. With the automation technique in the company, the jobs will shift and a decline in the workforce will be seen. The organization have 5 key areas in which it changes like work activity, workforce rules, the functioning of HR, setup of an organization, mindset 


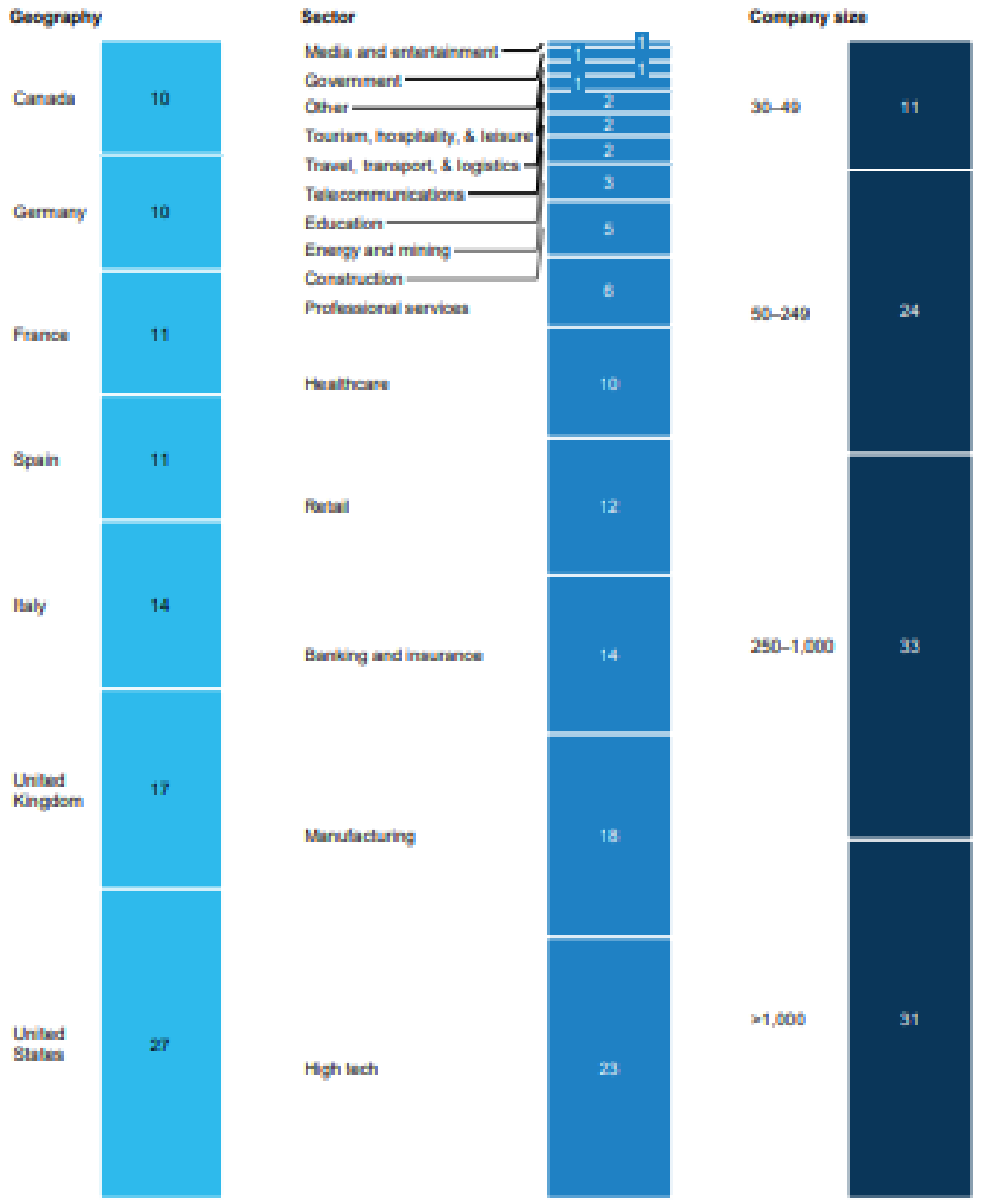

Fig 5: Impact of workforce in different sectors

\section{Conclusion}

The following research work tells us that, the workforce in earlier times was completely done by humans, and with the fast-growing technology the working conditions are changing with the change in the automated machines. A survey of the US and Europeans also gives a clear idea that different industries give different impacts on society. Like the work done in the oraganisation with the AI, it is believed that less manpower is required but it is not so because automation is d3pendenyt on the management skills that how it is managed and being utilized by the people in the organization. 


\section{References}

[1] M. Ansari, L. Ness, M. Rusinkiewicz, and A. Sheth, "Using Flexible Transactions to Support Multisystem Telecommunication Applications," Proceedings of the 18th Intl. Conf. on VLDB, August 1992.

[2] Action Workflow System product literature. Action Technologies Inc., 1993.

[3] https://www.sciencedirect.com/topics/computer-science/workflow-management-system

[4] https://www.forbes.com/sites/amitchowdhry/2018/09/18/artificial-intelligence-to-create-58-millionnew-jobs-by-2022-says-report/\#21a26574d4ba

[5] ElMaraghy W, ElMaraghy H, Tomiyama T, Monostori L. Complexity in Engineering Design and Manufacturing. CIRP Annals - Manufacturing Technolocy. 2012:793-814. [6]

[6] Axelos, "ITIL Service Strategy", 2011 Edition, United Kingdom, Axelos:ITIL official publisher

[7] Axelos, "ITIL Service Design", 2011 Edition, United Kingdom, Axelos:ITIL official publisher

[8] Axelos, "ITIL Service Transition", 2011 Edition, United Kingdom, Axelos:ITIL official publisher

[9] https://towardsdatascience.com/artificial-intelligence-will-make-the-workplace-more-human-not-less49af1ce6cd0d

[10] Rai, A., \& Sambamurthy, V, "Editorial notes-the growth of interest in services management: Opportunities for information systems scholars”, 2006, Information Systems Research, 17(4), pp. 327331.

[11] Cartildge, Alison et al., "An introductory overview of ITIL v3”, Londres: Capítulo do Reino Unido itSMF, 2007.

[12] Rosen, L. D., Whaling, K., Carrier, L. M., Cheever, N. A., \& Rokkum, J. (2013). The Media and technology usage and attitudes scale: An empirical investigation.

[13] Computers in Human Behavior, 29(6), 2501e2511. http://dx.doi.org/10.1016/j.chb.2013.06.006 